\title{
An apparatus for recording sucking and controlling feeding in the first days of life'
}

\section{A. J. Sameroff}

YALE UNIVERSITY

\begin{abstract}
An apparatus was described that can simultaneously record both the "suction" and "expression" components of the human newborn's sucking response. The apparatus also provides nutrient as a function of the performance of one or the other component. The apparatus is suitable for use in either operant or classical training of any sucking animal.
\end{abstract}

A central problem for human newborn research is the infant's limited ability to perform observable differentiated responses. A secondary problem is the investigator's ability to objectively record whatever responses the infant is able to make. The possibility of systematically studying the infant's ability to alter his sucking performance was suggested by a recent pediatric controversy on the nature of nutritive sucking. Two components of the sucking response were described for getting milk out of a nipple: "expression," squeezing the nipple between tongue and palate (Ardran, Kemp, \& Lind, 1958), and "suction," the generation of negative pressure in the mouth (Colley \& Creamer, 1958). Kron, Stein, \& Goddard (1963) designed an apparatus which could objectively record the suction component of the sucking response. The apparatus described here was

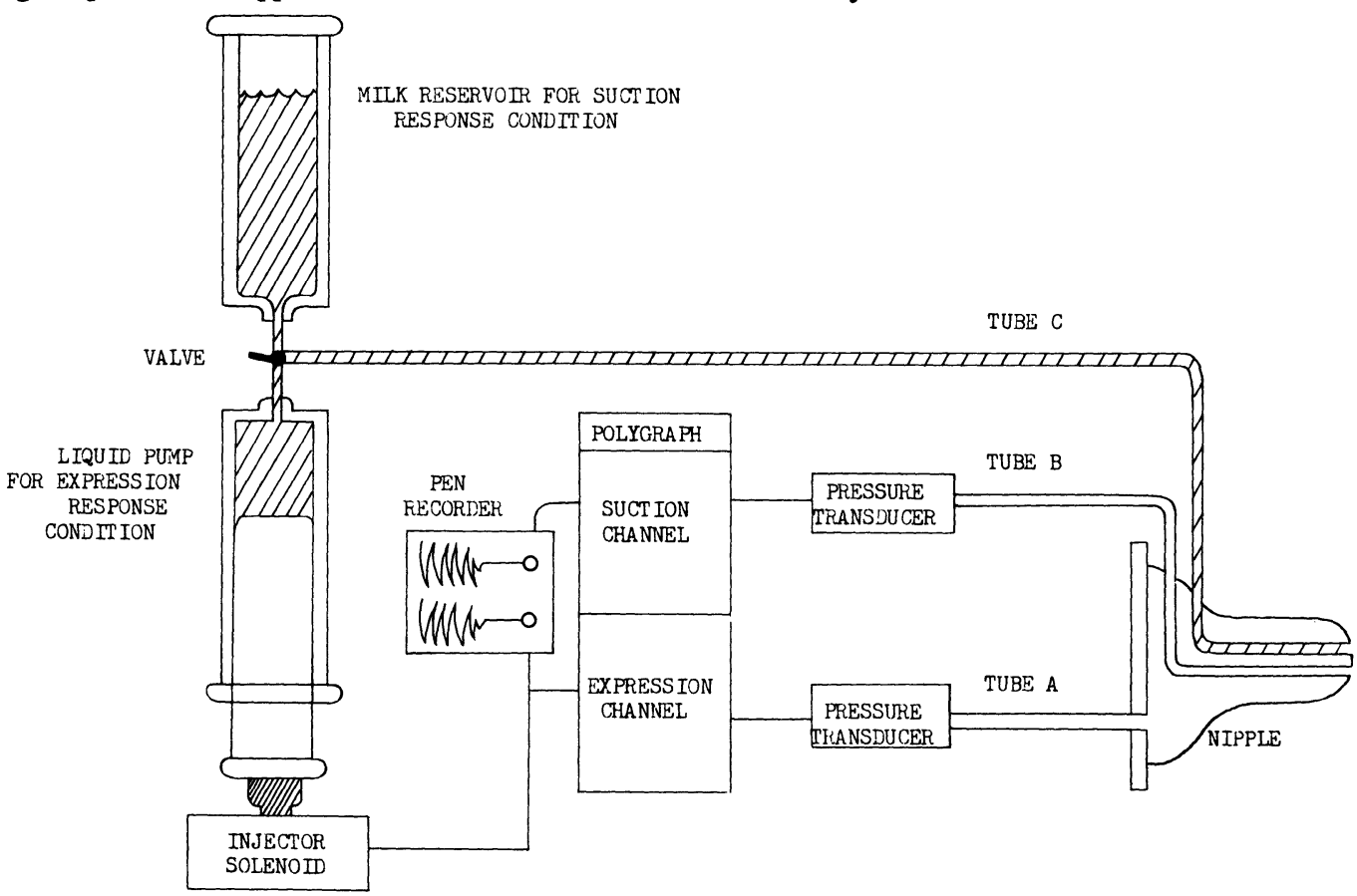

Fig. 1. Nipple and nutrient delivery system. designed (1) to record differentially expression (squeezing pressure) and suction (negative pressure applied to the tip of the nipple), and (2) to deliver nutrient differentially dependent on whether expression pressure is applied in one condition or suction pressure is applied in another condition (see Fig. 1).

The large open end of an Evenflo nipple was sealed with a plug containing a connection for a length of polyethylene tubing. The tubing $\left(I_{0} D_{0}=.125\right.$ in; shown as Tube A, Fig. 1) led to a Statham P23A pressure transducer which transmitted any pressure applied to the nipple to a Grass P51 preamplifier that served as one channel of a Grass P5D Polygraph Recorder. Two other polyethylene tubes $\left(I_{0} D_{0}=.034\right.$ in) passed through the nipple and up to the tip. The pressure in these tubes was independent of pressure changes within the nipple. One was used to measure negative suction pressure applied to the tip of the nipple (Tube B, Fig. 1) and was connected to another channel of the polygraph through a second pressure transducer. The other polyethylene tube (Tube C, Fig. 1) served as a delivery tube for nutrient.

In the suction response feeding condition, the delivery tube for nutrient was attached to a $50 \mathrm{cc}$ 
reservoir (Fig. 1); the $\mathrm{S}$ obtained nutrient by the application of negative pressure to the tip of the nipple. The level of nutrient was maintained even with the tip of the nipple so that no pressure differential developed. The amount of nutrient delivered was in direct proportion to the amount of suction applied to the nipple and mechanically independent of squeezing pressure on the nipple.

In the expression response feeding condi$\mathrm{t}$ i o $\mathrm{n}$, the nutrient delivery tube was attached to a $50 \mathrm{cc}$ syringe and plunger placed in a Davis LR-130 Liquid Pump (Fig. 1). The pump was activated to inject a discrete amount of nutrient into the S's mouth whenever the pressure in the nipple exceeded any specified threshold. The pulser of the liquid pump was operated by a relay placed in series with a variable resistor and the oscillograph output (plugs J5 and J6) of the polygraph channel recording expression pressure. By varying the resistance in the circuit, the pressure necessary to activate the pump could be varied. The amount of nutrient delivered was a simple function of the number of times the $\mathrm{S}$ squeezed the nipple with a pressure above the required threshold. Since the delivery system was closed, the amount of nutrient obtained was in- dependent of negative pressure applied to the nipple. Thus, each supra-threshold response resulted in the delivery of the same amount of nutrient.

It was also possible to use the pump delivery system in conjunction with the suction component. By placing the pump in series with the polygraph channel recording suction pressure, nutrient delivery would be on the same basis as in the expression response feeding condition. The amount of nutrient delivered would be a simple function of the number of times the $S$ applied suction pressure to the tip of the nipple above the required threshold.

\section{References}

ARDRAN, G. M., KEMP, F. H., \& LIND, J. A cineradiographic study of bottle feeding. Brit. J. Radiol., 1958, 31, 11-22.

COLLEY, J. R. T., \& CREAMER, B. Sucking and swallowing in infants. Brit. Med. J., 1958, 2, 422-423.

KRON, R. E., STEIN, M., \& GODDARD, K.E. A method of measuring sucking behavior of newborn infants. Psychosom. Med., 1963, $25,181-191$.

Note

1. Supported in part by Grant HD-00890 (formerly M-1787) awarded by the National Institute of Child Health and Human Development, United States Public Health Service, to William Kessen. The financial assistance of W. Kessen and the technological assistance of M. Haith is gratefully acknowledged. 